\title{
Web Based Emergency Information System for Reporting and Tracking of COVID-19 Infected Persons
}

\author{
Kanayo Kizito Uka1*, Ikechukwu Stanley Oguoma1, Chekwube Alphonsus Chukwu2, \\ Udochukwu Princewill Chuma-Uba ${ }^{1}$ \\ ${ }^{1}$ Department of Computer Science, Imo State University, Owerri, Nigeria \\ ${ }^{2}$ Nnamdi Azikiwe Teaching Hospital, Nnewi, Nigeria \\ Email: `kizzyict@gmail.com, oguomaikechukwu@gmail.com,dr.alphons@yahoo.com, michaelvalidprince@gmail.com
}

How to cite this paper: Uka, K.K., Oguoma, I.S., Chukwu, C.A. and Chuma-Uba, U.P. (2020) Web Based Emergency Information System for Reporting and Tracking of COVID-19 Infected Persons. E-Health Telecommunication Systems and Networks, 9, 17-32.

https://doi.org/10.4236/etsn.2020.92002

Received: May 11, 2020

Accepted: June 23, 2020

Published: June 26, 2020

Copyright $\odot 2020$ by author(s) and Scientific Research Publishing Inc. This work is licensed under the Creative Commons Attribution International License (CC BY 4.0).

http://creativecommons.org/licenses/by/4.0/

\begin{abstract}
Quick response to health related issues and reporting has been a huge problem associated with the Nigerian health sector especially when it comes to emergencies. The novel corona virus also known as COVID-19 has put not only the health practitioners into confusion but also to the general public. But in the fight for the solution of this huge pandemic, innovations and technological developments has also assisted in the fight to ensure that this deadly disease is defeated at once. Hence, this paper presents a web based emergency information system for reporting and tracking of COVID-19 infected persons as one of the innovations in fighting this infectious disease. The system is expected to provide a remote access for the general public to report any suspected person with COVID-19, enable questions to be asked, ensure that information on the case of infected and suspected persons with COVID-19 are tracked. This system was achieved following the Agile Model project development life-cycle and the Unified Modeling Language (UML) in respect to that, the front-end design was done with Hypertext Markup Language (HTML5), Cascading Style Sheet (CSS), JavaScript (JS) and Bootstrap Frame work while the back-end development was achieved with Hypertext Preprocessor (PHP5), and My-Structural Query Language (MYSQL). The result after design was a responsive and web based friendly platform for suspected and infected persons of COVID-19 to be reported, tracked and managed remotely.
\end{abstract}

\section{Keywords}

Web-Based, Infectious Illness, Coronavirus, Pandemic, Information System 


\section{Introduction}

The witnessed world pandemic caused by the deadly disease known as COVID-19 is a new respiratory infectious illness also called Coronavirus reported on December 31 by the World Health Organization [1]. It is a global health emergency issue that put the entire world into despair. The disease spread mainly through humans when they come close to each other (about 6 feet) and another through respiratory droplets from an infected person's cough or sneeze. Though many researchers, scientist is putting in their best to ensure that the treatment of this deadly disease is discovered. Furthermore, it was also identified that the symptoms of the disease includes: Fever, Cough and Shortness of breath or difficulty breathing. World governments are at work to establish countermeasures to stem possible devastating effects. Health organizations coordinate information flows and issues directives and guidelines to best mitigate the impact of the threat. At the same time, scientists around the world work tirelessly, and information about the transmission mechanisms, the clinical spectrum of disease, new diagnostics, and prevention and therapeutic strategies are rapidly developing. Many uncertainties remain with regard to both the virus-host interaction and the evolution of the epidemic, with specific reference to the times when the epidemic will reach its peak [2].

Currently, the therapeutic strategies to deal with the infection are only supportive, and prevention aimed at reducing transmission in the community is our best weapon. Aggressive isolation measures in China have led to a progressive reduction of cases in the last few days. In Italy, in geographic regions of the north, initially, and subsequently throughout the peninsula, political and health authorities are making incredible efforts to contain a shock wave that is severely testing the health system. Though in Nigeria, isolation centers has been put in place where medical doctors are battling day-in-day-out to ensure that the speed of the spread is reduced to its lowest level. It was noted after a critical study on the operations and activities in various isolation centers in the Country that the activities are manually operated, reporting and identifying of infected persons is difficult and hence making it impossible for the medical personnel's and the government to get accurate data and statistics of the infected persons in the country. Though there are some medical machines used in the diagnosis and treatment of this illness, but the major problem is inability to identify, track and report infected persons of this illness, therefore there is need to design a web based Emergency Information System for Reporting and Tracking of COVID-19 Infected Persons.

This system contribute immensely in the aspect of information gathering, discovery and reporting in the sense that enable people to easily report any suspected case of COVID-19 from a remote location, making it easier for the government to take adequate measure in identifying the person in question, and hence updating accurate information on the records of infected or suspected persons of COVID-19 within the country. In summary, the implementation of 
this system will provide an enabling platform for companies, public and private organizations and more importantly transportation companies to report suspected persons infected with COVID-19 infectious disease and hence making it possible for tracking and identification of these COVID-19 persons easily.

This paper is organized as follows: Introduction of the paper, related literature, role of information systems in fighting COVID-19 infectious disease, methodology, analysis of the existing system, analysis of the proposed system, new system architecture, use case diagram of the new system, activity diagram of the new system, high level model of the new system, sequence diagram of the new system information tracking, choice and justification of language platform, results and conclusion of the work.

\section{Related Literature}

[3] reported that the internet has changed the way people communicate and distribute information in all parts of the world. In 2005, about one billion people used the Internet [4], to exchange emails and instant messages, access information on web servers, and ever increasingly share files through various networks [5]. Information management system is said to be related components among themselves which work together with the aim of collecting, processing and saving of information distribution. [6] defined information management system as dignified computer system that accepts data, stores data, process and reports data from several sources to deliver necessary information to maintain and manage the process of making decisions while [7] explained an information management system by mentioning five responsibilities or activities shown in Figure 1 which are: data collection and process; Data analysis; Integration; Interface display and Information security. Data from various sources are turned into useful information through these activities. Management information systems consist of the

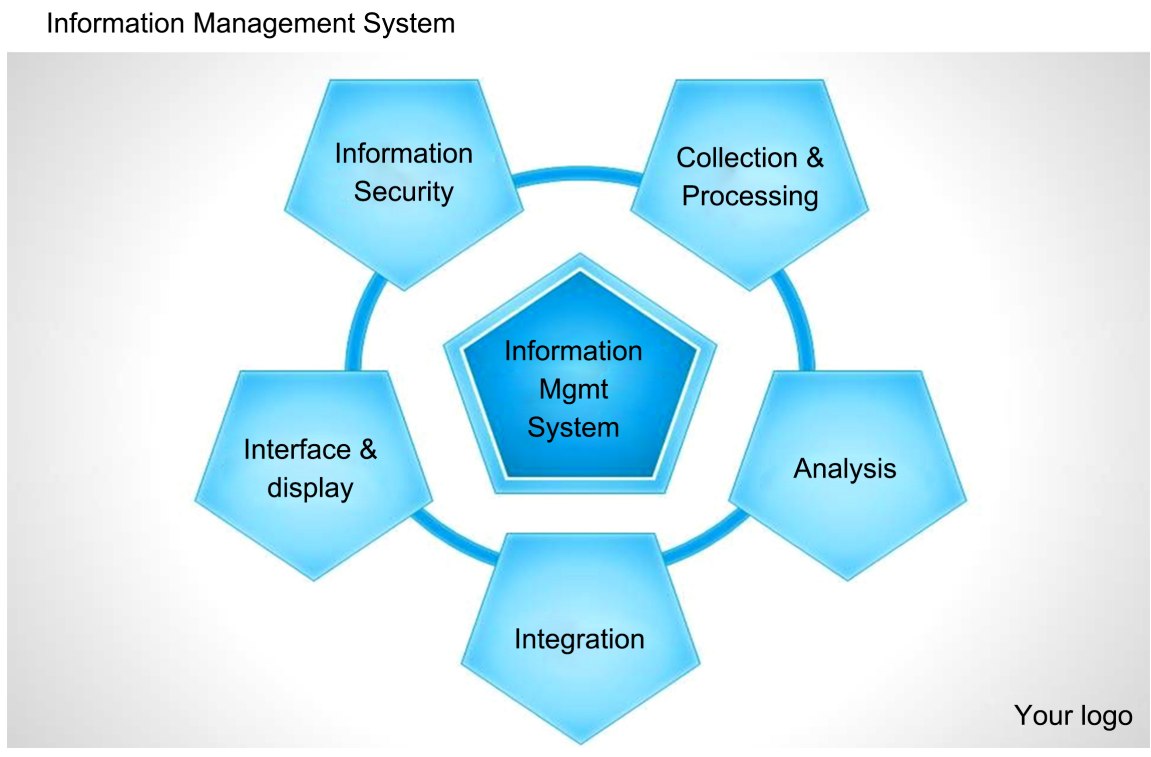

Figure 1. Information management system life-circle (Source: [7]). 
physical modules which include the hardware, software, databases, procedures and personnel. By [6] computing system is formalized system where collected data are sorted out by several processes, reports, data from numerous sources to provide the needed information and necessary to obtain necessary management decisions. Information system should be centered on the computer data, often collected and stored information automatically by process online.

\section{Role of Information Systems in Fighting COVID-19 Infectious Disease}

[8] noted that an information systems (IS) involve a variety of information technologies (IT) such as computers, software, databases, communication systems, the Internet, mobile devices and much more, to perform specific tasks, interact with and inform various actors in different organizational or social contexts. Of general interest to the field of IS are therefore all aspects of the development, deployment, implementation, use and impact of IS in organizations and society [9]. In respect to the role information system plays in providing a platform for the diagnosis, treatment, tracking, reporting and retrieving of related information's on the infectious disease called COVID-19. In this research, the researcher noted that information system (IS) is used by various IT organizations like Apple and Google as reported by Stan [10] designed a contact tracing system using a mobile phone Bluetooth to track infected persons with COVID-19 shown in Figure 2 below.

The companies designed the application in a way that enables public health organizations to keep track of everybody that users of the application come into contact with in a day. Therefore if someone with whom the user comes close with finally test positive after diagnosis, then the application will alert the user so as to take appropriate action. On the same hand, the Centers for Disease Control

Alice and Bob meet each other for the first time and have a 10-minute conversation.

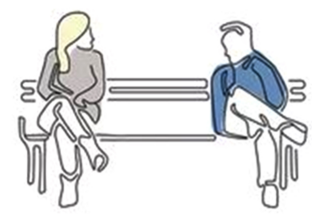

Their phones exchange anonymous identifier beacons (which change frequently).

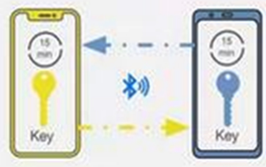

Bob is positively diagnosed for COVID-19 and enters the test result in an app from a public health authority.

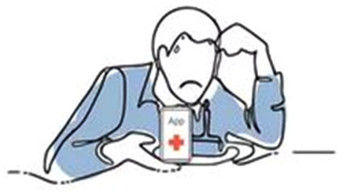

With Bob's consent, his phone uploads the last 14 days of keys for his broadcast beacons to the cloud.

Apps can only get more information via user consent

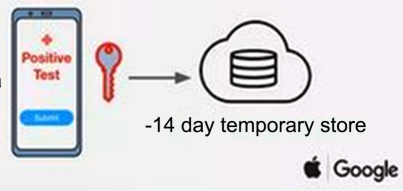

Figure 2. Apple and Google coronavirus tracking system into iOS and Android (Source: [11]). 
and Prevention [12] of United State of America has activated the Emergency Operations Center (EOC) which could assist the public health partners in replying or providing answer as they come in on the corona virus pandemic first acknowledged in Wuhan, Hubei Province, China. The organization tends to use their website to monitor the effects of this COVID-19 pandemic by updating their website on a daily bases as information comes in.

Furthermore, [13] designed its blood-based serology immunoassay kit which could help to diagnose SARS-CoV-2 (Virus that cause COVID-19) by analyzing a patient's immune system and hence watch it response against COVID-19 infectious disease and their platform could be operated manually or automated. In respect to the fight against COVID-19, china adopted some technologies like artificial intelligence (AI), big data, cloud computing, blockchain, and 5G which help to improve the efficiency and management, monitoring, virus tracking, prevention, control, treatment, and resource allocation of the epidemic as reported [14], some of the designed technologies includes: automated genomewide testing and analysis platform, temperature measurement technology based on computer vision and infrared technology used in checking body temperature in a contactless, reliable, and efficient manner, big data was used for prediction and early warnings of the disease, analyzing the flow of people and the distribution of materials and designing of Big Data Migration Map which allow people to use their phone to check for the migration trend of the Chinese mainland from the start till date, cloud computing was made free by Alibaba Cloud for public research institutions around the world for free to accelerate the development of new pneumonia drugs and vaccines, Online-Class was in high demand Youku and Ding Talk (an all-in-one platform under Alibaba Group) which allow students to attend class at home. The virtual and secured learning environment was equipped with adequate convenient learning tools, in the other hand, blockchain technology also help to provide maximum security towards making sure that data lose and alteration was not witnessed, and information tracing on corona virus within and outside the country is identified and aborted. In the aspect of $5 \mathrm{G}$, it was used in providing assistance towards management of this deadly pandemic; 5G was used to create live-streaming video and telemedicine systems, remote clinic consultation systems are developed in china and used in total fight against this disease [14].

In summary, so many technological devices and systems were developed and used in other Counties aside Nigeria as of the time of this research towards fighting this deadly disease, as outlined in section 2.1 of this paper. Hence, the key difference between this work and other existing related studies and adopted technologies on COVID-19 pandemic is outlined in Table 1. Therefore the new system uses a web base technology to proffer accurate and secured information gathering and provision to academic researchers, health professionals, government and developers within the country to fight against this pandemic called COVID-19 in Nigeria. 
Table 1. Major difference between the new system and the existing related literatures.

\begin{tabular}{|c|c|}
\hline Related Literatures & New System \\
\hline $\begin{array}{l}\text { Apple and Google reported by [10] designed } \\
\text { a contact tracing system using a mobile } \\
\text { phone Bluetooth to track infected persons } \\
\text { with COVID-19. }\end{array}$ & $\begin{array}{l}\text { The new system is an information platform } \\
\text { where people could report any suspected } \\
\text { person infected with COVID-19. } \\
\text { - It is more like a website for information } \\
\text { reporting and tracking. }\end{array}$ \\
\hline $\begin{array}{l}\text { - A center for Disease Control and Prevention } \\
\text { [12] is a website for providing answers for } \\
\text { people on the case of COVID-19. } \\
\text { This website only allows people to ask } \\
\text { questions and they provide answers to } \\
\text { their questions. } \\
\text { - It only store questions and answers asked } \\
\text { by people. }\end{array}$ & $\begin{array}{l}\text { The new system is also a website for } \\
\text { reporting of suspected persons with } \\
\text { COVID-19 Case. } \\
\text { - The new system helps in collecting and } \\
\text { storing of valid data of persons with } \\
\text { COVID-19 cases and storing in the cloud. }\end{array}$ \\
\hline $\begin{array}{l}\text { - }[13] \text { designed its blood-based serology } \\
\text { immunoassay kit } \\
\text { Online-Class: Youku and Ding Talk (an } \\
\text { all-in-one platform) by Alibaba Group } \\
\text { using Cloud Computing Technology. }\end{array}$ & $\begin{array}{l}\text { - The new system used web services } \\
\text { technology to design a platform for } \\
\text { information reporting, tracking of } \\
\text { suspected persons with the virus. }\end{array}$ \\
\hline
\end{tabular}

\section{Methodology}

The methodology adopted for the design of the new system was agile model and Unified Modeling Language (UML). The UML was used to model various users' activities and their privileges on the platform. This model was used because of the emergency of the COVID-19 pandemic; it requires a fast approach towards providing solutions that could help in solving the problem at hand. An agile model allows developers to carry out a project in an iterative approach, open collaboration, and process adaptability throughout the life-cycle of the project. In this approach, repeated visit to every phase of the work is done until its final development is achieved.

The development of the web based emergency information system for reporting and tracking of COVID-19 infectious disease followed the repetition process as shown in the Figure 3 to achieve the desired objectives of the new system.

\subsection{Analysis of the Existing System}

The existing system of information gathering, tracking and retrieving in Nigeria towards management of the COVID-19 outbreak are handled manually and unprofessional. There was no platform for people to report suspected persons with COVID-19. That is to say, reporting of cases of COVID-19 is done mainly in the isolation centers, and hence most times the law enforcement agencies are not able to identify person that entered in the country either because of bribe or no proper technology to do so. In transportation companies in Nigeria today, people still travel from state to state without proper medical checks for COVID-19, and 


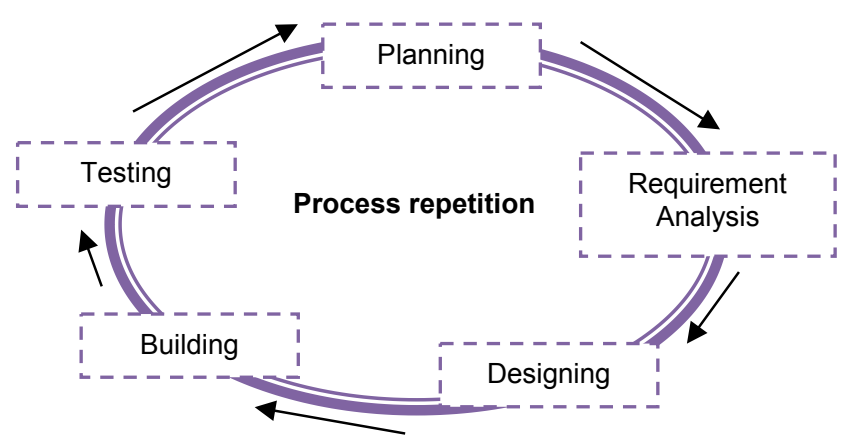

Figure 3. Agile model project life-cycle flow.

even if the medical checks are done, fast reporting or call to COVID-19 emergency response team are not fast contacted, therefore, the new system is designed to fill in this gap by providing a platform for private, public organizations, people to provide information on suspected persons with COVID-19 after medical examinations conducted. Furthermore, because recording of infected or suspected persons of COVID-19 is done manually made accurate data storing, retrieving, tracking and update difficult and time wastage sometimes leading to data lose. "There is no how restrictions to accurate data to researchers and technologist will not affect the rate of technological advancement or products development that could assist the medical personnel's and government fight the corona virus". It was because of access to this information's that made china design numerous technological devices that helped manage the disease in their country. Therefore, the researchers urge the Nigerian government to build a data bank or warehouse (if not in existence) and make it open for researcher and technologist to use in building software's and hardware's or techniques that could help in managing this deadly disease.

\subsection{Analysis of the Proposed System}

The proposed system architecture shown in Figure 4 contains all the modules and how they are inter-connected to each other. The proposed system also is composed of two different users; People user and administration as shown in use case diagram in Figure 5. The Use case diagram provides a clear privileges and role of each user on the platform. The new system activity diagram shown in Figure 6 of this research explains the activities of various users on the platform. Once a user visits the platform through the browser, the first point will be the control panel (Home) which can now provide a link for login authentication process to be done. After a successful login authentication process, the user with (People Role) can report a case nor ask questions concerning the pandemic while the user with (Administrator Role) could track for information on the spread, affected or suspected persons with COVID-19 within the country, updating of information on the pandemic, and providing accurate answers to questions asked by people on the issue of the pandemic while Figure 7 outlined the High Level Model (HLM) of the new system and how all modules and 


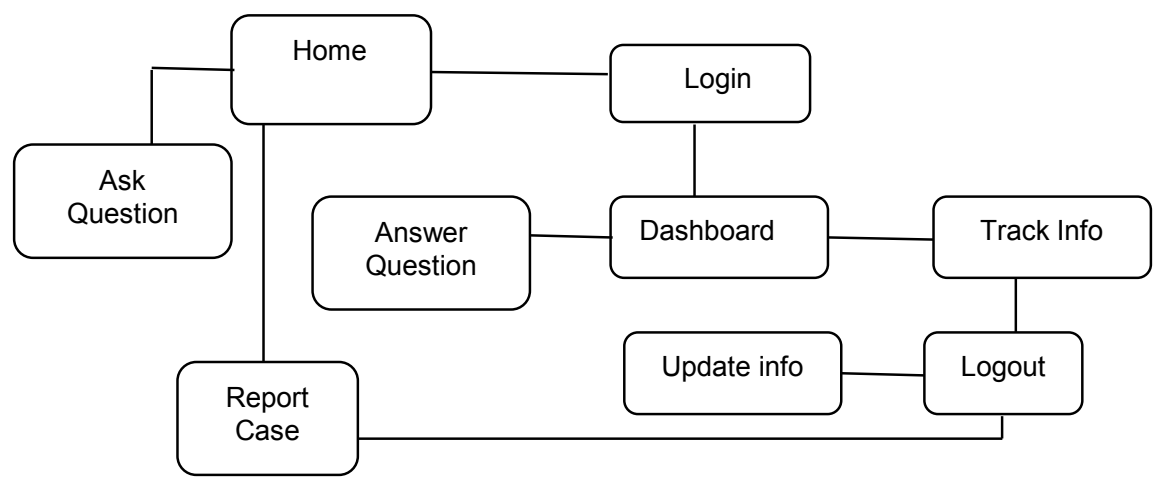

Figure 4. Architecture diagram of web based emergency information system for reporting and tracking of COVID-19 infected persons.

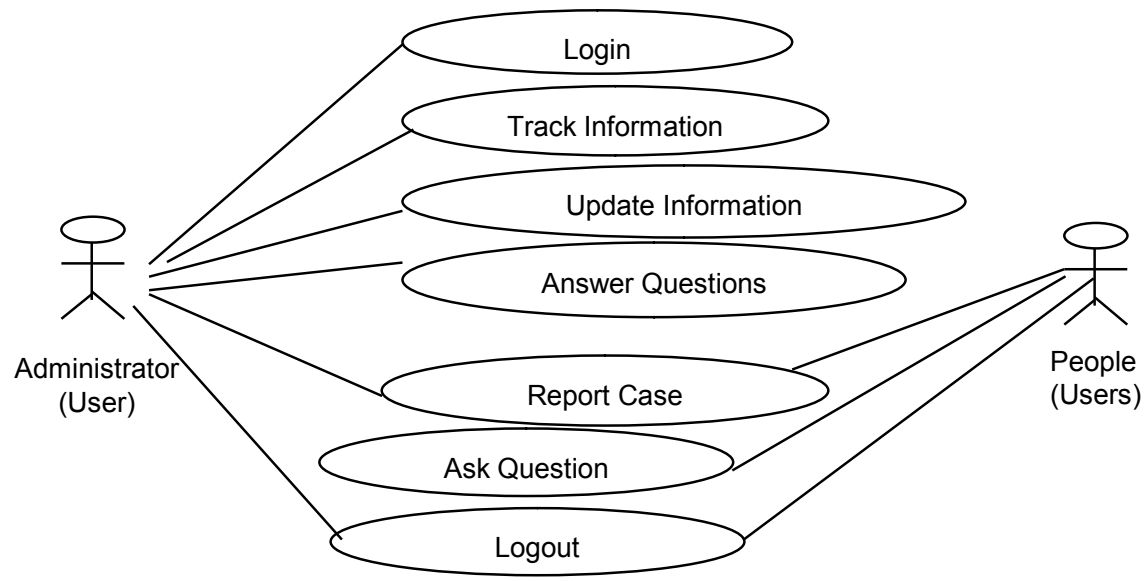

Figure 5. Use case diagram of the new system.

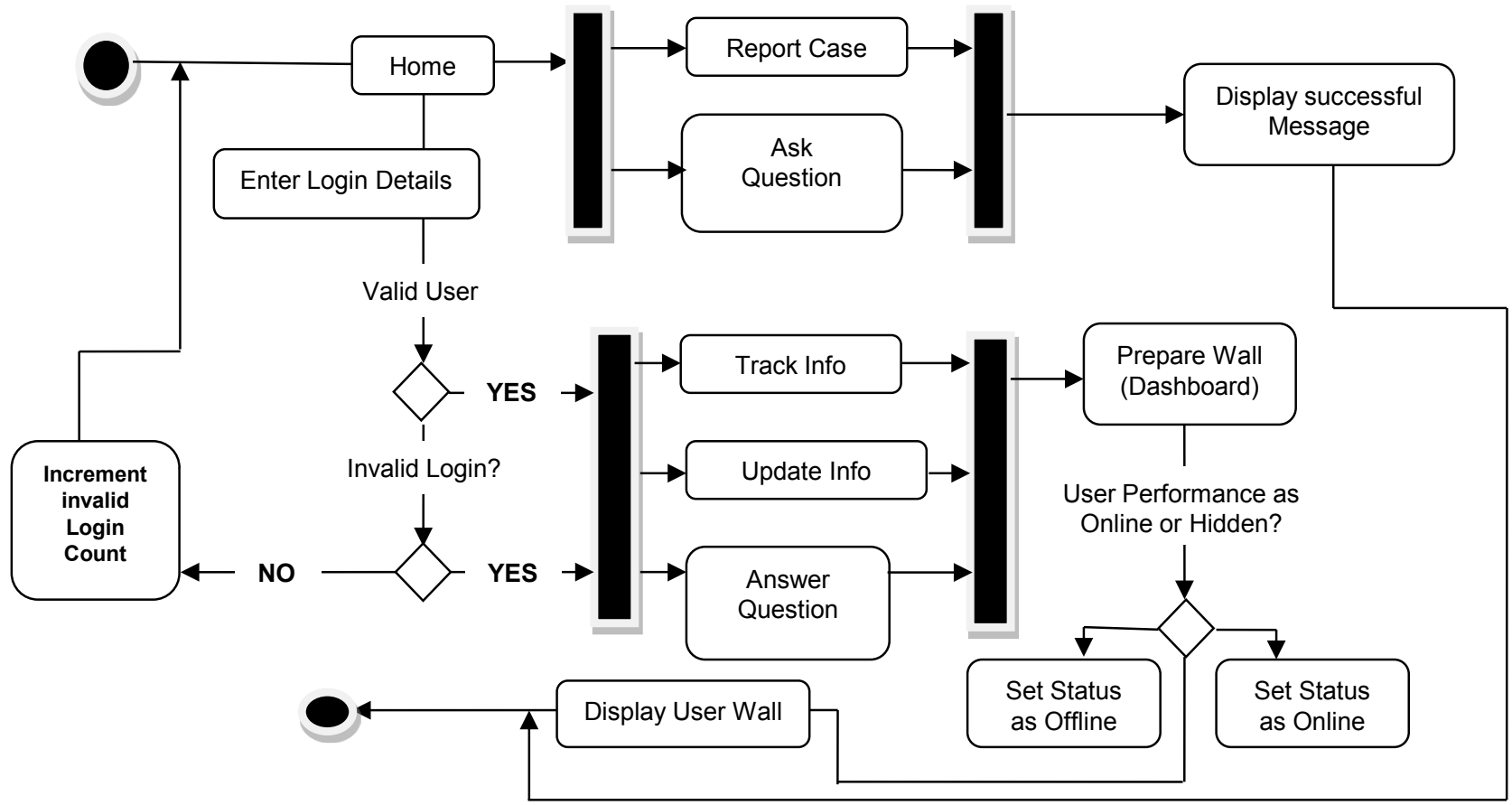

Figure 6. Activity diagram of the new system (Source: Fieldwork 2020). 


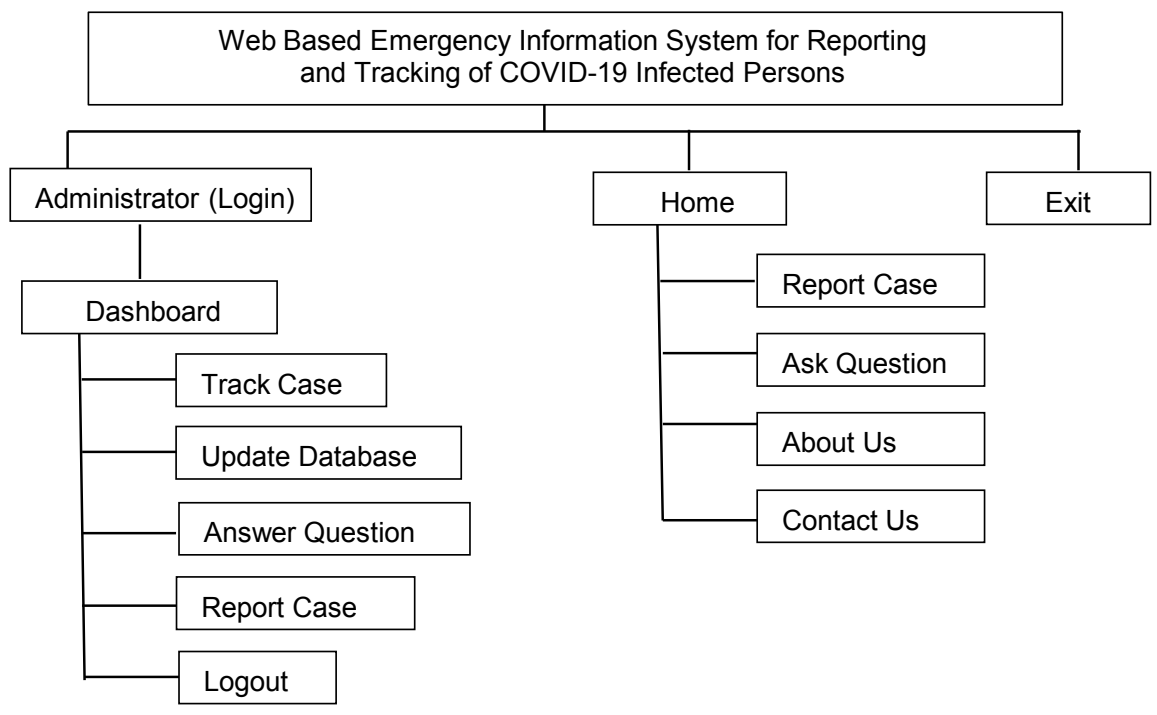

Figure 7. High level model of the new system.

sub-sub-modules are inter-related. Every system must have a style (method) of operation, hence the Figure 8 shows the Sequence Diagram of the new system information tracking, once a successive login is done which will take the user to the dashboard, the dashboard enable user to either to Track a Patient, Answer Question, Update Patient Information and management of the entire system.

- PEOPLE USER: The general public accesses the platform through their mobile phone web browser by entering the URL of the website. Once the interface opens, the HOME of the platform (index.php) displays links to every other module the user wishes to access depending the role and access shown in Figure 9. As a user with this role has ability to report any suspected person with the virus by clicking on the Report Case Module (Report_Case.php) to report a case. Figure 10, shows the COVID-19 Case reporting interface. Also ability for more enlightenment on the issue of COVID-19 could be achieved through the interface in Figure 11, it was identified that people are afraid and are not informed properly on the causes and dangers of this disease, therefore the interface, allow for questions to be asked by the people on the case of this pandemic (Ask_Question.php).

- ADMINISTRATOR USER: Before an administrator could access the dashboard, shown in Figure 12, an authentication of the login details will be done and this authentication will be achieved on the interface (Login.php) shown in Figure 13 after which an access could be granted into the dashboard (Dashboard.php) for other activities. The administrator role allow access to track suspected person by clicking on the module (Track_Case.php) shown in Figure 14 so as to periodically monitor the patient health status. The administrator user is the one with the entire control and management of the system. The admin is privileged to update the system database shown in Figure 15 by clicking on the module (Update_Info.php) at any time to feed in the rightful information, the admin role also click on the module shown in 


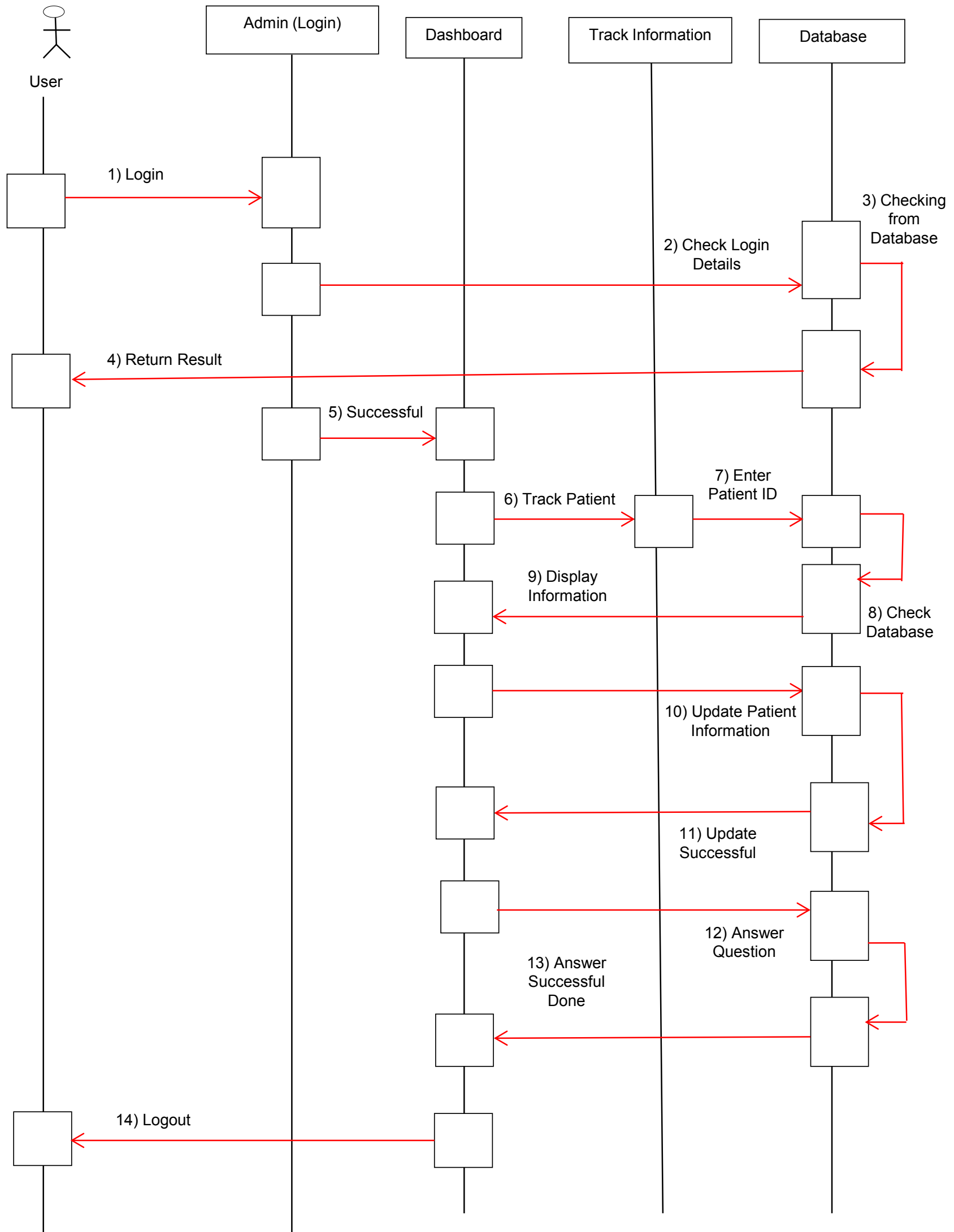

Figure 8. Sequence diagram of the new system information tracking (Source: Fieldwork 2020). 


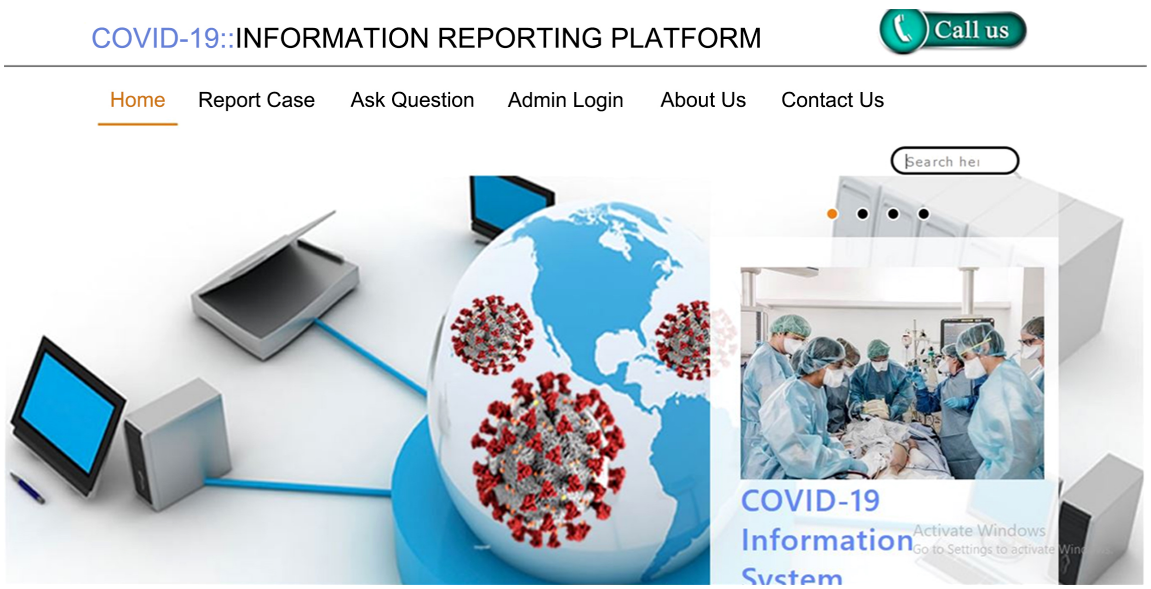

Figure 9. The control center of the information system (HOME) (Source: Fieldwork 2020).

COVID-19 CASE REPORTING INTERFACE

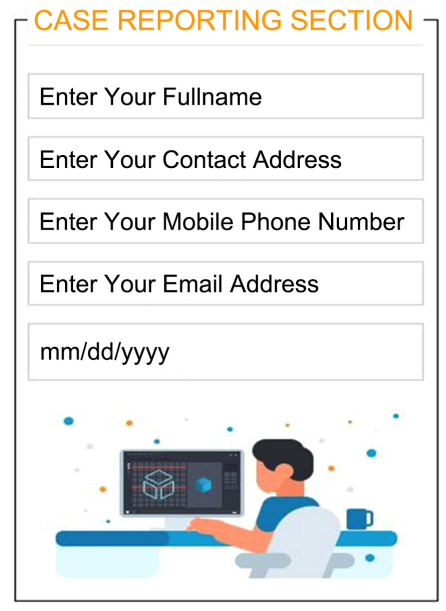

SUSPECTED COVID-19 PERSON

\begin{tabular}{|l|}
\hline INFORMATION \\
\hline Enter Fullname (AKA) \\
\hline Enter Location \\
\hline Enter Complexion \\
\hline Enter Name of Transportation Company \\
\hline Enter Destination of the Person \\
\hline Enter State Identifield \\
\hline Enter City \\
\hline $\mathrm{mm} / \mathrm{dd} / \mathrm{yyyy}$ \\
\hline
\end{tabular}

SUBMIT REPORT NOW

Figure 10. COVID-19 case reporting interface (Source: Fieldwork 2020).

ASK QUESTION ON COVID-19 PANDEMIC

$\times$

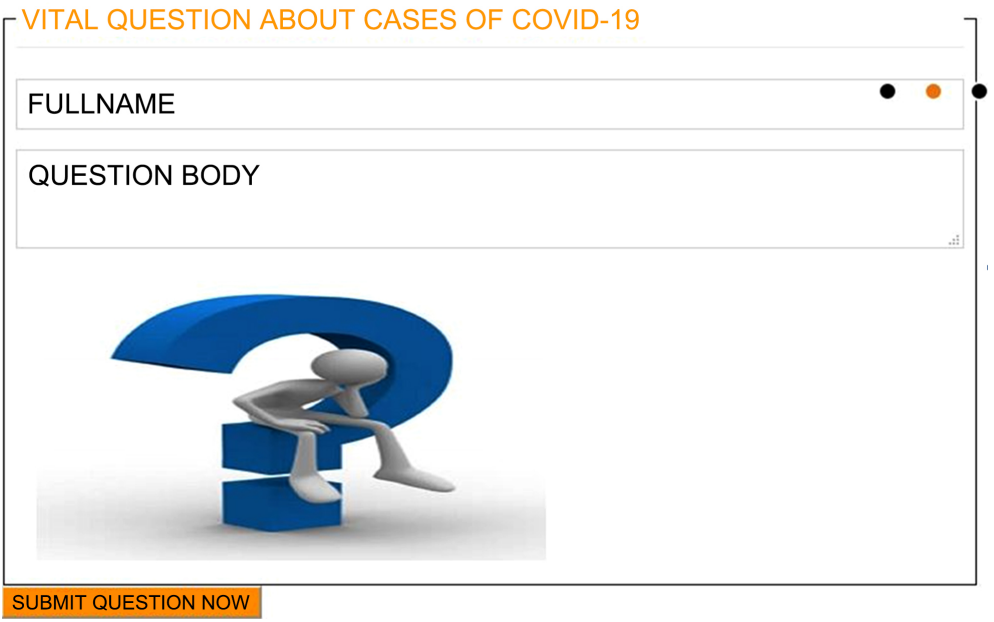

Figure 11. Ask question on COVID-19 pandemic (Source: Fieldwork 2020). 


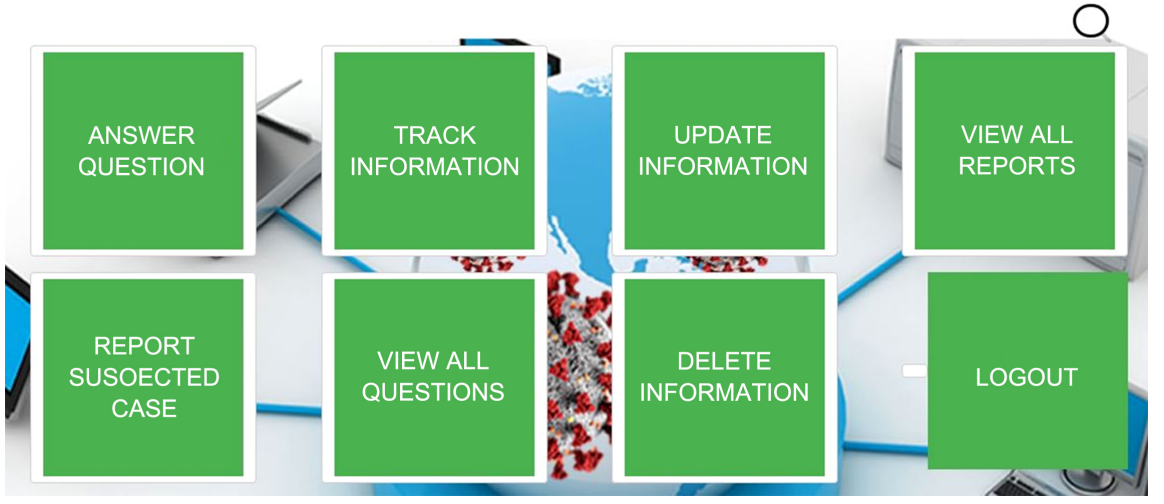

Figure 12. Administrator dashboard (Source: Fieldwork 2020).

\begin{tabular}{l} 
ENTER VALID USERNAME AND PASSWORD \\
COMBINATION \\
\hline Enter Your username \\
Enter Your Password
\end{tabular}

Figure 13. Administrator login interface (Source: Fieldwork 2020).

TRACK REPORTED CASE OF COVID-19 PANDEMIC

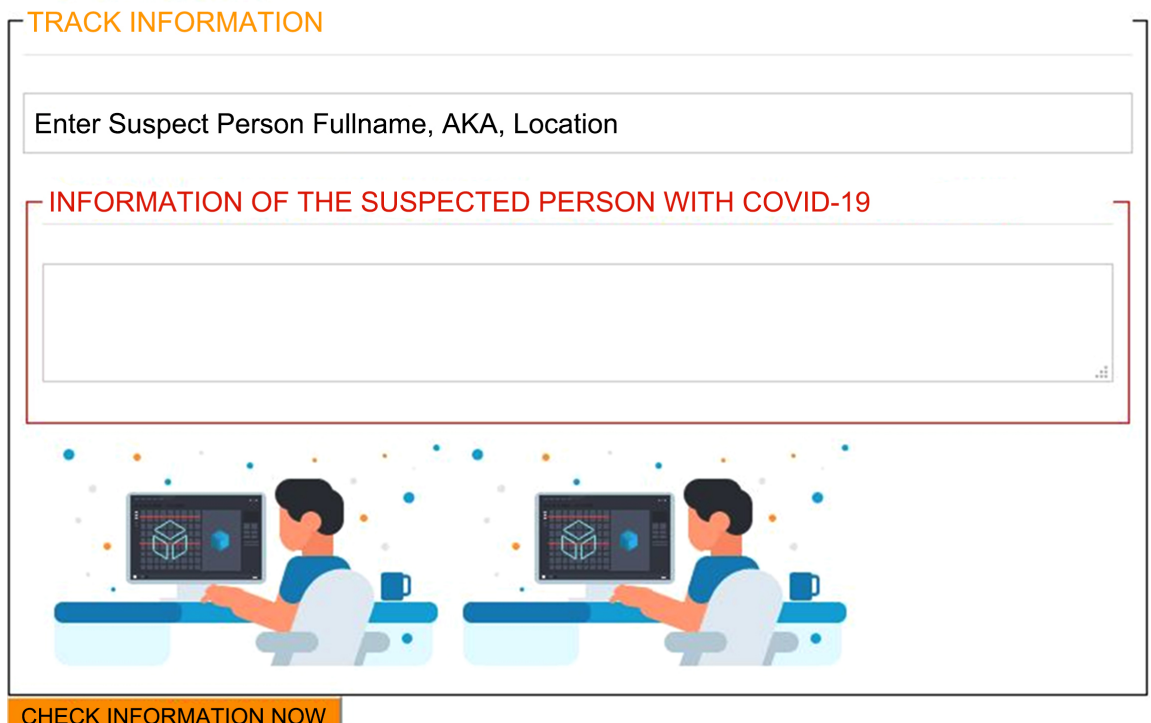

Figure 14. Track reported case of COVID-19 (Source: Fieldwork 2020). 
Figure 16 (Anwser_Questions.php) to proffer answers to questions asked by people. The administrator role must have a unique username and password combination before proceeding for the activities on the platform. Finally, the administrator role also could delete any information from the database base on a certain condition shown in Figure 17.

UPDATE INFORMATION

UPDATE INFORMATION IN

DATABASE

Enter Your Fullname

Enter Your Contact Address

Enter Your Mobile Phone Number

Enter Your Email Address

$\mathrm{mm} / \mathrm{dd} / \mathrm{yyyy}$

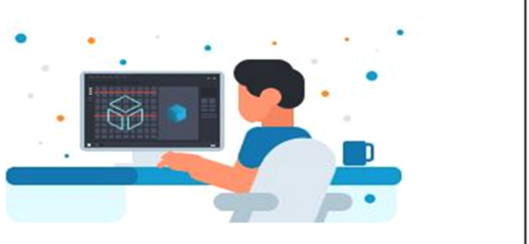

\section{SUBMIT REPORT NOW}

Figure 15. Updating information in the database (Source: Fieldwork 2020).

ANSWER QUESTION ON COVID-19 PANDMIC

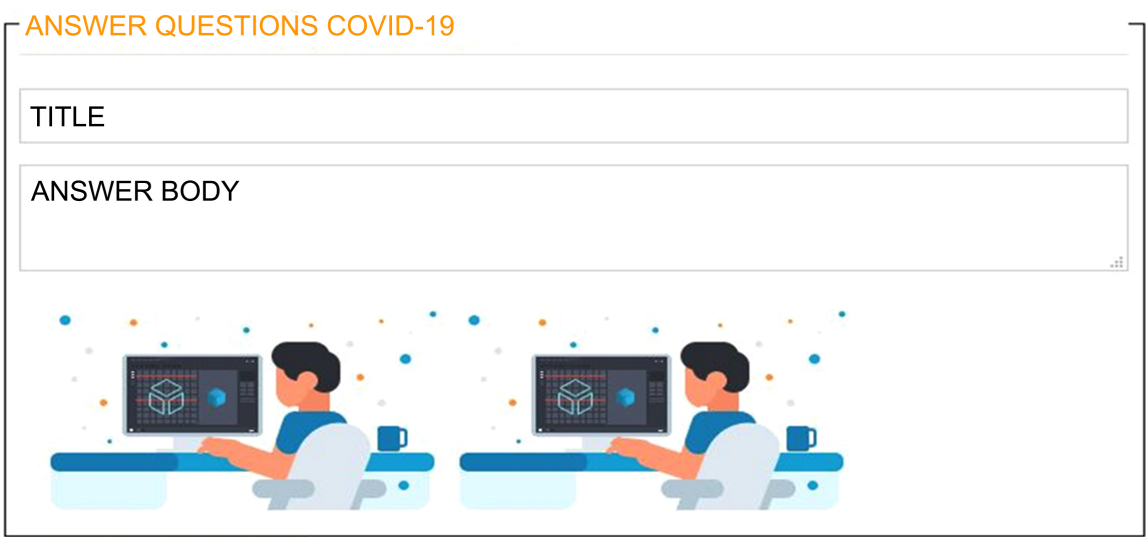

SUBMIT QUESTION NOW

Figure 16. Provide answers to questions on COVID-19 (Source: Fieldwork 2020).

DELETE INFORMATION FROM DATABASE $\quad \times$

ENTER DATA ID MUMBER:

DELETE RECORD NOW

Figure 17. To delete information from the database (Source: Fieldwork 2020). 


\subsection{New System Architecture}

The architecture of the new system contains modules of the web based information system for tracking and reporting of infected persons with COVID-19 shown in Figure 4. The architecture view tries to show the modules in the system and how they are connected to each other hence giving more clear understanding of the operations are carried out effectively and efficiently online.

\subsection{Use Case Diagram of the New System}

The use case diagram of the new system explains various users and their various privileges and role on the platform. The administrator user has the role of tracking information on the issue of COVID-19 cases, constant update of the information's as of when due, providing accurate answers to questions asked by people on the current pandemic and report any suspected case of the pandemic. On the same platform, the people user has some granted privileges such as to report any suspected case of COVID-19 within the country, and ask questions about the disease where necessary.

\subsection{Activity Diagram of the New System}

The new system activity diagram shown above explains the activities of various users on the platform. Once a user visits the platform through the browser, the first point will be the control panel (Home) which can now provide a link for login authentication process to be done. After a successful login authentication process, the user with (People Role) can report a case nor ask questions concerning the pandemic while the user with (Administrator Role) could track for information on the spread, affected or suspected persons with COVID-19 within the country, updating of information on the pandemic, and providing accurate answers to questions asked by people on the issue of the pandemic.

\subsection{High Level Model of the New System}

The new system High Level Model (HLM) was designed using the Unified Modeling Language (UML) tool; it was done following the top-down design technique, such that every module, sub-module and sub-sub-module in the system was captured shown in Figure 7 of this paper.

\subsection{Sequence Diagram of the New System Information Tracking}

The Sequence Diagram of the New System Information Tracking outlines various activities in a sequential order for the administrator user on the platform. The system checks admin (user) login details from the database, if login combination is false, an errorresult is displayed for the user else, a successful message which will take the admin (user) to the admin dashboard where operations as shown in Figures 14-16 and Figure 17 of this paper can be performed. After successive activities on the platform are done by the admin (user), the logout link used to exist from the dashboard. 


\subsection{Choice and Justification of Language Platform}

The new system is a web based emergency information System for reporting and tracking of COVID-19 Infected Persons. The front-end development was deployed using Hypertext Makeup Language (HTML5), Cascading Style sheet (CSS), Bootstrap Framework, and JavaScript (JS) while the backend of the system was deployed using Hypertext Preprocessor (PHP5) and My-Structural Query Language (MySQL) to achieve the desired web base platform. The software development environment used was Sublime integrated Development Environment (IDE).

\section{Results}

This section contains the output (results) screen shot of the new System. It shows the implementation phase and to enable the readers to a more understanding on how the new system could be used to report or track cases of COVID-19 in Nigeria. Figure 9 shows the control center (index.php) of the entire system. It is the first interface a user meets after entering the Universal Resource Locator (URL) of the website in the browser.

To effectively report cases of COVID-19 in Nigeria, this interface shown in Figure 10 ensure that all reported case are adequately submitted into the database for immediate action to be taken place.

The administrator of the system also has the privilege to delete irrelevant information's from the database periodically. This can be achieved through the interface shown in Figure 17.

\section{Conclusion}

In conclusion, information systems has been used in all aspect of effective data management, therefore in the aspect of the new identified Corona virus infectious disease was also managed with the developed web based emergency information System for reporting and tracking of COVID-19 Infected Persons in Nigeria. Hence the system was able to store reported cases of COVID-19, questions and answers on the disease were adequately done and store for future reference, monitoring of affected and suspected persons were collected and stored, and lastly the web platform was accessible for every person with availability of computer device either mobile phone or PCs remotely. Hence the authors therefore recommend that this system be adopted by the Nigerian government to help in the fight against Corona virus infectious disease.

\section{Conflicts of Interest}

The authors declare no conflicts of interest regarding the publication of this paper.

\section{References}

[1] WHO (2019) Coronavirus Disease 2019. 
https://emedicine.medscape.com/article/2500114-overview

[2] Cascella, M., Rajnik, M., Cuomo, A., Dulebohn, S.C. and Di Napoli, R. (2020) Features Evaluation and Treatment of Coronavirus (COVID-19). https://www.ncbi.nlm.nih.gov/books/NBK554776/

[3] Uka, K.K., Oguoma, S.I. and Chuma-Uba, U.P. (2020) Analysis of Blockchain Architecture in File Sharing Management for Tertiary Institution. Inteligent Information Management, 12, 88-104. https://doi.org/10.4236/iim.2020.123007

[4] Rajendran, R.K. and Rubenstein, D. (2004) Optimizing the Quality of Scalable Video Streams on P2P Networks. Proceedings of GLOBECOM, Vol. 2, November 2004, 953-959. https://doi.org/10.1145/1005686.1005735

[5] Karagiannis, T., Broido, A., Brownlee, N., Claffy, K. and Faloutsos, M. (2004) Is P2P Dying or Just Hiding? Proceedings of GLOBECOM, Vol. 3, December 2004, 1532 1538 .

https://www.academia.edu/15035384/Information Systems and Information Tech nology

[6] Hicks, J.O. (2003) Management Information System. 3rd Edition, Virginia Polytechnic Institute and State University.

http://www.tutorialspoint.com/management concepts/decision making process.htm

[7] Slideteam.net Information Management.

https://www.slideteam.net/0514-information-management-system-powerpoint-pres entation.html

[8] Boell, S.K. and Cecez-Kecmanovic, D. (2015) What Is an Information System. 48 th Hawaii International Conference on System Sciences.

https://www.researchgate.net/publication/271588444 What is an Information Sys tem

[9] Orlikowski, W.J. (1992) The Duality of Technology: Rethinking the Concept of Technology in Organizations. Organization Science, 398-427.

https://doi.org/10.1287/orsc.3.3.398

[10] Horaczek, S. (2020) Apple and Google Plan to Track COVID-19 Using Your Phone's Bluetooth.

https://www.popsci.com/story/technology/google-apple-coronavirus-app/

[11] Brandom, R. and Robertson, A. (2020) Apple and Google Are Building a Coronavirus Tracking System into iOS and Android.

https://www.theverge.com/2020/4/10/21216484/google-apple-coronavirus-contracttracing-bluetooth-location-tracking-data-app

[12] Centers for Disease Control and Prevention (CDC-2020) CDC Emergency Operations Center Activations. https://emergency.cdc.gov/recentincidents/

[13] Bio-Rad (2020) Bio-Rad to Launch Blood-Based Immunoassay Kit to Detect Covid-19. https://www.medicaldevice-network.com/news/fda-coronavirus-test/

[14] Qi, X.X. (2020) How Next-Generation Information Technologies Tackled COVID-19 in China.

https://www.weforum.org/agenda/2020/04/how-next-generation-information-techn ologies-tackled-covid-19-in-china/ 